\title{
Socio-cultural factors to breaking through the glass ceiling: A case study of university of Ghana, Legon
}

\author{
Hannah Benedicta Taylor-Abdulai ${ }^{1,}{ }^{*}$, Lipsey Samuel Appiah-Kwapong ${ }^{1}$, Grace Sintim-Adasi ${ }^{1}$, \\ Emelia Sarpong ${ }^{1}$, Akosua Darkwa ${ }^{2}$ \\ ${ }^{1}$ Accra Polytechnic, Accra, Ghana \\ ${ }^{2}$ Department of Sociology, University of Ghana, Legon, Ghana
}

Email address:

hbta30@gmail.com (H. B. Taylor-Abdulai)

\section{To cite this article:}

Hannah Benedicta Taylor-Abdulai, Lipsey Samuel Appiah-Kwapong, Grace Sintim-Adasi, Emelia Sarpong, Akosua Darkwa. Socio-Cultural Factors to Breaking through the Glass Ceiling: A Case Study of University of Ghana, Legon. Social Sciences.

Vol. 3, No. 5, 2014, pp. 170-176. doi: 10.11648/j.ss.20140305.14

\begin{abstract}
The study looked at socio-cultural factors that impede women faculty career progress. A total of 142 faculties made up of 33 females and 109 males were sampled for the study using a stratified sampling strategy from the faculties, schools and institutes. Using a mixed method, the study compared male and female faculty of the University of Ghana, Legon using a proxy of roles and responsibilities both at home to find out which gender has more responsibilities in taking care of family and home. The findings in the study show the prevalence of subtle gender discrimination mechanisms that hinder women's opportunities for career advancement and other career opportunities. The study shows that the university does not effectively create the necessary conditions to support mothers with children under two years. The invisibility of female faculty is as a result of their roles as wives and mothers, which invariably leaves them with little or no time to participate in informal networks. The study found that many women than men experience conflict regarding their ability to simultaneously play the role of wife, mother and worker. The study recommends that in order for the University of Ghana, Legon to retain those women who are already in the system, it is necessary to give them responsibilities that would increase their skills in leadership positions. Structural changes, such as "family friendly" policies in the form of flexible faculty meeting time may also be helpful so that female faculty with children can participate effectively in the university.
\end{abstract}

Keywords: Glass Ceiling, Socio-Cultural Barriers, Gender, childcare

\section{Introduction}

Throughout most of the twentieth century, there was an unconscious and unquestioned assumption, in maledominated organisations, that a woman should retire, if not after marrying, then certainly after the birth of any children [1]. Sutherland [2] pointed out that although many women no longer had to sacrifice their careers in this way by the early1990 s, it was still a widely held view that women should remain at home during their children's formative years. Indeed, she observes that some of the women academics involved in her study shared this view. She also makes the important point that the decision to have a family can affect career progression. Nevertheless, even if women academics postpone having children until after they have completed a $\mathrm{PhD}$ and post-doctoral work, the arrival of young children often coincides with the age when they are still expected to make an impact in their chosen fields through high-quality research and a regular output of publications.

Studies have shown that women in academia have a difficult task of combining multiple roles as mothers and wife and that make it difficult for them to move ahead in their career tracks as fast as men $[3,4,5,6,7,13,14]$. This is intimated by de la Rey [4] study, where majority of women mentioned that childcare and other family responsibility accounted for obstacles and challenges they face as academicians. Forester [5] in a case study conducted with 112 women in British Universities concludes that over 80 percent of the participants believe that family responsibilities have interfered with their career progression and 4 out of 5 still have the primary responsibility for childcare. Moreover, it has been suggested that the primary responsibility for housework and childcare shouldered by the majority of employed women entails their working a "second shift" [5] 
and that the problems of balancing the demands of a career and family life inhibit the realization of the career potential of women academics.

\section{Aim of the Study}

The aim of this paper is to explore the socio-cultural barriers that hinder faulty members from getting to higher echelon of academia.

\section{Methods}

The various Faculties, Schools and Institutes in the University of Ghana were put into clusters, respondents were chosen from all the clusters, through simple random

sampling after stratifying for gender; 20 percent of the population of faculty was selected based on the proportion of both female and male faculties. The study was descriptive and cross sectional using a mixed method to collect data. Quantitative methods took the form of administration of questionnaires to 142 faculties; made up of 33 female and 109 male faculties. Analyses of these were purely quantitative. It therefore emphasized on precision and generalized statistical findings and the qualitative was indepth interviews with 10 faculties; five females and five males were purposively selected for the interview. Content analysis was used for the qualitative data, themes were developed based on the research questions.

\section{Presentation of Findings}

Table1. Background characteristics of Respondents

\begin{tabular}{|c|c|c|}
\hline \multirow{2}{*}{ Background characteristics } & Female $\mathbf{N}=33$ & Male $N=109$ \\
\hline & Percent & Percent \\
\hline \multicolumn{3}{|l|}{ Marital status } \\
\hline Single & 15.2 & 10.1 \\
\hline Married & 75.7 & 88.1 \\
\hline Widowed & 3.0 & - \\
\hline Divorced & 6.1 & 1.8 \\
\hline \multicolumn{3}{|l|}{ Highest degree } \\
\hline MA & 3.0 & 0.9 \\
\hline LLM & 3.0 & 1.8 \\
\hline MSc & 3.0 & 2.8 \\
\hline MBA & 3.0 & - \\
\hline MFA & 3.0 & - \\
\hline M.Phil & 30.3 & 30.3 \\
\hline MD/MPH & - & 1.8 \\
\hline $\mathrm{PhD}$ & 39.4 & 57.8 \\
\hline $\mathrm{MD} / \mathrm{MPH} / \mathrm{PhD}$ & 9.1 & 3.7 \\
\hline Others & 6.1 & 0.9 \\
\hline \multicolumn{3}{|l|}{ Rank } \\
\hline Tutor & 6.1 & 2.8 \\
\hline Asst. lecturer & 3.0 & 0.9 \\
\hline Lecturer/Res. Fellow & 45.4 & 57.8 \\
\hline Snr. Res. Fellow/Senior Lecturer & 42.4 & 27.5 \\
\hline Associate Professor & - & 5.5 \\
\hline Professor & 3.0 & 5.5 \\
\hline \multicolumn{3}{|l|}{ No. of years on current rank } \\
\hline $1-4$ years & 60.7 & 40.6 \\
\hline $5-9$ years & 28.6 & 41.6 \\
\hline $10-14$ years & 10.7 & 10.9 \\
\hline $15-19$ years & - & 6.9 \\
\hline
\end{tabular}

\section{Marital Status of Respondents}

Out of the 33 female respondents, 5.2 percent were single as compared to 10.1 percent male faculty in the same category; 75.7 percent female faculty were married as against 88.1 male faculty. Three percent female faculty said that they were widowed whilst there was no male faculty that had been widowed. About 6 percent female faculty said that they had been divorced as compared to 1.8 percent male faculty. Table 1 indicates the marital status of faculty:

To situate the problem of progression of both genders, it was important to look at how far both genders have progressed in terms of promotion. It is apparent in higher education where female faculty are rarely full professors, and, if they are, it is in the humanities; as a general rule, the lower the faculty rank, the higher the percentage of female $[6,7,8,9]$.

The highest degree of respondents is indicated in Table 1. Female faculty represents the highest percentage in the lower degrees, except in ${ }^{1} \mathrm{MD} / \mathrm{MPH} / \mathrm{PHD}$ where female faculty accounted for 9.1 percent. Female faculty who hold MA were 3.0 percent whilst male faculty accounted for 0.9 percent. For LLM degree, female faculty accounted for 3.0 percent whilst male faculty accounted for 1.8 percent. For those who hold MSc, female faculty accounted for 3.0 percent whilst male faculty account for 2.8 percent; female 
faculty accounted for 39.4 percent in all PHD holders whilst male faculty accounted for 57.8 percent.

On the issue of number of years spent on current rank, out of the 33 female faculty sampled 28 of them indicated the number of years that they had spent on their current rank. Close to 61 percent female faculty had spent between one and four years; 28.6 percent had spent between five and nine years on current rank whilst 10.7 percent had spent between fourteen and nineteen years on current rank. On the other hand, 40.6 percent of male faculty had spent between one and four years on their current rank, 41.6 percent had spent between five and nine years, 10.9 percent had spent between ten and fourteen years on current rank whilst 6.9 percent had spent between fifteen and nineteen years. In general, length of time spent on a particular rank depends on the individual faculty. However, all male faculty interviewed said even though they were qualified for promotion, they were preoccupied with other things they considered more important than applying for promotion. On the other hand, some female faculty interviewed complained that they have had to stay long on their current rank because processes for promotion is too long, aside that they thought it was a deliberate attempt to stifle their effort. Another female faculty said she had to spend so long a time because it was difficult getting researchable topics in her field of study.

Data from Table 1 indicate that women in academia were less likely to be married as compared to their male counterparts and also end up being divorced than their male counterparts. This is because being single and childless gives more room for independence and more concentrated on career. Among faculty members who had children the male faculty had larger number of children than the female, an indication that their wives who were the primary care takers bore the responsibility of taking care of the children and not them. Table 2 shows the number of children of respondents

Table 2. Number of children of Respondents.

\begin{tabular}{lll}
\hline \multirow{2}{*}{ No. of children } & Female $\mathbf{N}=\mathbf{2 8}$ & Male $\mathbf{N}=\mathbf{9 6}$ \\
\cline { 2 - 3 } & Percent & Percent \\
\hline One & 28.6 & 8.3 \\
Two & 32.1 & 26.0 \\
Three & 25.0 & 37.5 \\
Four & 10.7 & 21.9 \\
Five & 3.6 & 3.1 \\
Six & - & 3.1 \\
Total & 100.0 & 100.0 \\
\hline
\end{tabular}

Childcare is one of the difficult challenges women face in their careers. This is because, the formative years of children are very important for mothers as well as children to grow and establish some bond between mother and child. In the same vein, the academic clock does not wait for women who become pregnant and take time off to raise them. The study therefore sought to find out respondents who had children and those who had taken care of them at their formative years.

On the issue of caring for children when they were/are under school age, 20.7 percent of female faculty said that their children were primarily cared for by themselves as compared to 11.4 of male faculty. On the other hand, only 6.9 percent female faculty reported that their partners had cared for their children under school age as compared to 20.5 percent of male faculty's partners. This is an indication that women continue to shoulder the responsibility of their children whilst they were still young and needed attention irrespective of one's profession. Interestingly, 55.7 percent male faculty reported having equal share between them and partner, indicating egalitarian relationship as compared to 44.8 percent of female faculty. About 7 percent female faculty reported that children under school age were primarily taken care of by a combination of family members as compared to 10.2 percent male faculty. Indicating that the external system continue to be useful as far as caring of children is concerned.

\section{How Respondents' Children under School are Taken Care}

Apart from the career interruptions for family reasons, another factor that had often been quoted to explain limited female careers is related to the assumption of responsibility for childcare. The interviews revealed in a rather obvious way that more male faculty delegated the care of their children to their partner, whilst female faculty had to struggle from work to home to take care of their children. About 14 percent female faculty reported that their children under school age were primarily taken care of in privately financed care as compared to 2.2 percent of male faculty.

The question of whether the issue of children after school hours impairs faculty ability to perform job was asked. About 21 percent of female faculty said that it never affected them as compared to 43.8 percent male faculty. 65.5 percent female faculty reported that it affected them sometimes as compared to 48.9 percent male faculty; 13.8 percent female faculty reported that it affected them very often as compared to 7.3 percent male faculty.

\section{How Issues of Children's After School Hours Impair Respondents' Ability to Perform}

On the issue of conflict between the demands of work at the university and that of life outside work, female faculty who reported that they had not experienced any conflict were 20.7 percent as compared to 27.4 percent male faculty, whilst 65.5 percent female faculty as compared to 54.7 male faculty said that it sometimes affected them. Surprisingly, 13.8 percent female faculty reported that they very often experience a conflict as compared to 17.9 percent of male faculty. This finding could be as a result of male faculty sharing equal responsibility with their wives.

Women have made significant inroads in education albeit the glass ceiling. This has made quite a number of women 
more willing to postpone marriage and sacrifice not to give birth while they pursue career goals as compared to men who can conveniently sacrifice the private spheres for the public sphere. About 36 percent of female respondents and only 9.3 percent male faculty reported that they had very often made personal sacrifices to get to where they are today. Literature on professionals and interviews with faculty reveals that either professional woman abandon the idea of having children or if they decide to have one, they have children later on when their career is on track. Western literatures on women in academia assert that female faculty starts having children when they attain tenureship.

The question of not having children or delay in having children was posed; about 63 percent female faculty reported that they never had to make such sacrifice as compared to 51.5 percent male faculty. Twenty percent female faculty reported that they considered such sacrifice as compared to 36.1 percent male faculty; whilst 16.7 percent female faculty reported that they had actually delayed in having children as compared to 12.4 percent male faculty.

The interviews revealed that some male faculty had to delay marriage in order to obtain their doctoral degrees and for that matter, even though they are quite old their children are very young. A female faculty on the other hand, said she has dedicated her entire life to her career and for that matter; she has no family of her own. This is a typical example that confirms Currie et al. [10] assertion that academia is a greedy institution.

In the private sphere, which is traditionally female domain, there is some form of revolution. Female faculty who reported not doing domestic work at all was about 9 percent as compared to about 6 percent for male faculty. This is in contrast to literature on women which say that domestic work belonged to the private sphere. However, the fact still remains that women are primary care givers. About 12 percent of female faculty and 7 percent male faculty reported that they completely took care of domestic work in the household. Table 3 shows the responses of faculty members.

Table 3. Extent to which respondents take care of domestic work

\begin{tabular}{llc}
\hline $\begin{array}{l}\text { Extent to which respondents } \\
\text { take care of domestic work } \\
\text { in the household: }\end{array}$ & Female $\mathbf{N}=\mathbf{3 3}$ & Male $\mathbf{N}=\mathbf{1 0 9}$ \\
\cline { 2 - 3 } & Percent & Percent \\
\hline Not at all & 9.1 & 5.5 \\
Less than half & 24.2 & 56.9 \\
Half & 21.2 & 18.3 \\
More than half & 33.3 & 12.0 \\
Completely & 12.1 & 7.3 \\
Total & 100.00 & 100.00 \\
\hline
\end{tabular}

$[11,12$,$] have shown that career women are more likely$ than their men counterparts to interrupt their career. Data from the survey indicate that more female faculty, 27.3 percent as compared to 11.5 percent had had interruptions longer than six months in their academic career. Various reasons had been given for such interruptions. For those who have ever had interruptions in their career longer than six months, 27.3 percent female faculty reported that they had had interruptions as compared to 11.5 percent male faculty. The reasons assigned for the interruptions were: child rearing 44.4 percent for female faculty, 11 percent female faculty attributed the interruption to financial expediencies as compared to 18.2 percent male faculty. Another 11.1 percent female faculty said that they needed change in academic field, as compared to 9.1 percent male faculty. No female faculty reported having left academia in pursuit of political expediencies as compared to 54.5 percent male faculty. For faculty who left for educational pursuit, 33.3 percent were female faculty and 54.5 percent male faculty.

Table 4. Reasons for interruptions

\begin{tabular}{lll}
\hline \multirow{2}{*}{ Because of: } & Female $\mathbf{N = 9}$ & Male $\mathbf{N}=\mathbf{1 1}$ \\
\cline { 2 - 3 } & Percent & Percent \\
\hline Child rearing & 44.4 & - \\
For financial reasons & 11.1 & 18.2 \\
Change of academic field & 11.1 & 9.1 \\
Political activities & - & 18.2 \\
Educational pursuit & 33.3 & 54.5 \\
Total & 100.0 & 100.0 \\
\hline
\end{tabular}

The data reflect the relatively high level of collective assumption that women are responsible for children in Ghanaian society [3]. In some instances, the extended family plays an important role in the care of young ones. Obviously, the existence of the collective childcare structures neither mean that women are relieved off this "mental pressure" to take care of the children, nor that these services allowed them to do freely all the activities related to an academic career, for example travelling to participate in conferences. The data from the interview corroborates that of the quantitative data. When questioned about the relationship between work and family, both women and men faculty said that they experienced some form of work-family spill over.

According to Lambert [13], in this process the emotions, behaviours and attitudes are carried out from work to family and vice-versa. However, the negative spill over and the situations of work-family conflict were more evident in the case of women. Three women in the sample described familiar situations where the husband's lack of support emerged as one important source of conflict. During the interviews, a female faculty made these statements concerning the work-family conflict:

“... I had to go abroad to get my Ph.D. at a time I had a young child and I did not want to leave her behind. My husband also encouraged me even though it was a difficult situation. It was more or less conflicting relationship; I decided having the PhD abroad. I don't see myself as the ideal mother for my child I have my work, and obviously I want to be married and have children, I think that I have already made some sacrifices, namely, I don't go abroad to attend conference sometimes, as I think I should have done. In addition, there were times when I needed to work hard, I did not give up my work, and I had to repeatedly hear my husband say, "You don't need to work, you shouldn't be working today". I often work Saturdays and Sundays preparing notes for 


\begin{abstract}
Monday and I sometimes have to deal with very unpleasant situations created by my husband.

I do not have his support as I think that I should have. I end up not being the wife that he wanted me to be, he wanted someone totally devoted to him, and I don't fit in that role"
\end{abstract}

In other cases, despite the husband's support, women's work-family conflict is associated with time constraints due to the enormous responsibilities of taking care of their children and having to work longer hours. For the majority of women in the interview the responsibility for the care and well-being of their children are borne by relatives who, in a way have helped reduced the burden on their (women) career.

On the other hand, only three men described situations of work/family conflict, but they were mostly feelings of personal guilt for spending little time with family especially with children. On the other hand, for most men the relationship between work and family is depicted as a supportive one, with their wife's understanding of the high demands of an academic career. The following quotations illustrate this point:
"My family is very supportive, there is a lot of understanding my wife and other family members take care of the home".
Another male faculty comments that:
"There is a lot of support; I think that there is a good understanding of my absences. When we have time constraints workwise, we have to find some extra-time in the family time... Nevertheless, I feel I have great support and trust from my family. The family, in my case, has given me strong support and incentive that has been very important indeed! When I was doing my PhD, she [the wife] relieved me of domestic tasks (errands I need to run for the home)."

The interviews revealed that although both men and women experience work-family conflict, they do it differently. For men it was a question of regret for not being able to spend more time with their children. For women it was exhaustion from trying to play and to adjust to two different roles. In this sense, these women viewed time required by children as a serious barrier to their career progress.

The findings also revealed that little has changed in society in terms of who is responsible for looking after the children and for household chores. Even though hiring domestic help can be a form of coping strategy, the ultimate responsibility for children and domestic tasks invariably seems to rest with women. In this study, six of the married participants (two women and four men) stated that the women (the interviewees or the interviewees' wives) kept the full responsibility for childcare and domestic tasks. The following illustrations depict very well how the traditional gender division of roles at home remains unchanged:
"My wife is mainly responsible for the family; she's the one that takes care of most domestic work. This gives me more free time to invest in my career and more freedom to travel when I need..." (Male faculty)

"I'm mainly responsible for the family sphere. In practice, I have to divide my efforts by multiple tasks, taking the kids to school, but I get someone to take them from school, and when they are at home around four o'clock and, from then on, I can do my work....." (Female faculty)

Two single women faculty said marriage and motherhood are considered very distant realities and important constraints detrimental to their career prospects. It must be underlined that these women who are single and without children, still hold a very traditional image about the gender division of roles in family. For them, little has changed in terms of gender stereotypes and gender roles and attitudes hence, their decision to postpone child bearing.

Women still bear the burden of domestic responsibilities. As [14] underline, "western societies have achieved some progress towards gender equality in the public sphere of the labour market, but gender inequality in economic roles in the household may be more resistant to change". Such a resistance to change in the private sphere helps keep gender inequalities and patriarchal structures in society. These patriarchal structures are, nevertheless, not only sustained by men but also by women that are socialised into believing that domestic tasks are for women and not for men. A senior female faculty observes;

\footnotetext{
"Women were raised to know how to support all the family responsibilities. Thus, they are more skillful than men for doing these tasks. On the other hand, women know how to be multifunctional but men do not. Women are able at the same time to hold a child, prepare food, pick up the telephone, but if I tell my husband who is reading the newspaper to see if the onion is burning, it definitely ends up burned. In my opinion, men do not have the ability to be multifunctional."
}

The socialisation process in childhood has continuous effects in adult behaviour. Both men and women help to perpetuate a social system where women remain disadvantaged in the private/home sphere. Inevitably, men and women are still socialised to perform traditional roles and as long as this continues, gender inequalities in work settings will remain. The majority of women in this case study try to combine family and work but give priority to their family. Single women in this sample do not permanently refuse the idea of having a family. However, they have decided to primarily invest in their career development.

Finally, the paper confirms that mobilisation of women on domestic activities in terms of the reproduction role is definitely much higher than that of their male colleagues.

The work culture in some departments emphasises the need to work long hours and weekends and to be competitive if someone wanted to be successful. This does not offer 
female faculty with young ones the opportunity to contribute effectively since they have to carry on the spill over from work to home and vice versa.

\section{Discussions}

Childcare and domestic work is all structural factors that have affected women possibilities of shattering the glass ceiling. If it is more profitable for women than for men to stay at home when the children are small, it will affect their chances of advancement within the organisation. To think of a career woman being pregnant for nine months and exclusively breastfeeding for six months is a difficult task for women in academia since missing out for all these months would mean being less productive. It becomes practically impossible for women to obtain the same merits, and compete on the same terms as men if structural factors, directly or indirectly, hold them back. The study therefore confirms other findings [3, 13, 14, 15, 16, 17] that female faculty roles as workers, mothers and wives impede their advancement in academia.

A female head of a section confessed that she spends very little time with her family since she leaves the house very early and gets home later in the evening at about seven. Unmarried female faculty in the study attest to the fact that they virtually spend most of their time preparing for academic activities and not making time for other social activities. Again, this is example that academia is a greedy institution. The paper again supports $[3,14]$ work which indicates that women in academia have a difficult task of combining multiple roles as mothers and wives and that make it difficult for them to move ahead in their career tracks as fast as men.

The findings show that more women do more than half of domestic work in the household than men. This paper supports [2, 4, 13, 14] studies, where majority of women mentioned that childcare and other family responsibilities account for the obstacles and challenges they face as academicians. However, like in most African societies the external family has an important role to play in supporting working mothers to take care of the children as well as the home, but that does not completely relieve women of the responsibility of caring especially for the young.

Data from the survey indicates that more women have had to make personal sacrifices concerning their career by delaying childbirth and have had interruptions in their career to have babies. According to the women interviewed, women are required to be involved in both family and work.

In typical Ghanaian circles society expect women to combine everything very smoothly and nobody expects that from men, that they combine both roles very well, it is enough that they are good professionals. Women have to be good professionals on one hand, but, on the other hand, they cannot harm their children by neglecting them when they are young. When men do not give much importance to their family, they are not seen as harming their family but are taking care of their lives; if women are taking care of their professional lives, they are seen as harming their children. The problem in our society is that now women have to handle both roles, not just one, they have to deal with both.

One must underline the dominant view of career in the lives of women as a means of both economic and social empowerment. Marshall [18] indicated that careers should be interpreted as a sequence of jobs within and between organisations rather than as a steady climb up to the organisational ladder. This demands the reinvention of the career concept allowing women and men to take career breaks whenever they feel necessary [19, 20, 21].

The majority of women and men in this sample still believe that equal opportunities between the sexes can only be achieved through individual solutions. They seem to ignore that it is impossible to achieve equality as long as the gender division of roles remain. As underlined by Ferreira [22], the creation of equal opportunities between the sexes remains confined to the private realm through the confrontation between women and men, while the institutions that are responsible for the promotion of equality between the sexes remain absent and without responsibilities on this matter.

As stated by Arber and Ginn [12], the inequalities in the private sphere change very slowly because women themselves contribute to perpetuate the traditional gender role division due to the socialization process that sustains a masculine ideology. However, as studies have shown, if women are to achieve equality with men, it must be in both the labour market and the domestic sphere and changes have to be carried out in both realms and not just in the private sphere [1, 2, 12, 18, 19]. Therefore, changes have to be triggered in both spheres of an individual's life. It is not only the division of labour at home that limits women's possibilities of choosing work orientation and career pattern, but research has shown that horizontal gender segregation partly has to do with individual and rational choices [20, 21, $22,23,24,25,26]$.

\section{Conclusion}

Despite the changes in attitudes towards women's academics, they are still hampered by the existence of gendered values and attitudes towards their non-work responsibilities.

\section{References}

[1] Bradley, D. (1993). A foot in the door: women in employment, education and training in Australia, Unicorn, 19(1):15-27

[2] Sutherland, M. (1985), Women Who Teach in Universities, Trentham, London.

[3] Prah M. (2002) "Gender Issues in Ghanaian Tertiary Institutions.” In Ghana Studies 5, Pages 83, 122

[4] de la Rey. (1998) South African Women in Higher Education.A Review of their Experiences. Penguin Fastprint. Pgs.5-20 
[5] Forster N. (2001). A case study of women academics' views on equal opportunities, career prospects and work-family conflicts in a UK University Career Development International 28 - 38

[6] Hochschild, A. (1989). The second shift. New York: Viking.

[7] Headlee, S.(1996), the cost of being female. Fraeger Publishers 88 Post Road West, West Post

[8] Currie, J. et.al (2002), Gendered Universities in Globalized Economies: Powers, Careers and Sacrifices, Lexington Books, New York.

[9] Davidson, M.J. \& Cooper, C.L. (1987). Female managers in Britain: A comparative perspective. Human Management Resource, 26 pages 217-242.

[10] Strober, M. (1982) "The MBA: Same Passport to Success for Women and Men." In Phyllis Wallace, (ed) Women in the Workplace. Boston, MA: Auburn House Publishing, p. 25-44.

[11] Lambert, S. J. (1990).Processes linking work and family: A critical review and research agenda. Human Relations, 43 (3), 239-257.

[12] Arber, S. and Ginn, J. (1995). The mirage of gender equality: occupational success in the labour market and within marriage. British Journal of Sociology, 46 (1), 21-43.

[13] Cole, J. R., \& Zuckerman, H. (1991). Marriage, motherhood, and research performance in science. In H. Zuckerman, J. R. Cole, \&J. T. Bruer (Eds.), The Outer Circle: Women in the Scientific Community (pp. 157-170). New York: W. W. Norton and Company.

[14] Taylor, H. B. (2007). The nature of glass ceiling in Ghanaian Universities: A case study of University of Ghana, Legon. An unpublished M.Phil dissertation. University of Ghana, Legon. Pg $95-105$

[15] Taylor, H. B. (2003). The nature of glass ceiling in a service industry; a case study of S.I.C. An unpublished post graduate diploma dissertation. University of Ghana, Legon pages 20-29
[16] Wirth L. (2001). Breaking through the Glass Ceiling: Women in management. Geneva, International Labour Office (pg.25147)

[17] Hochschild, A. (1989). The second shift. New York: Viking.

[18] Marshall, C. (1984). From culturally defined to self-defined: Career stages of women administrators. Nashville, TN: Vanderbilt University. (ERIC Document Reproduction Service No. ED 272 968)

[19] Barinaga, M. (1992). Profile of a field: Neuroscience - the pipeline is leaking. Science. 255(13 March), 1366-1368.

[20] Brush, E. G., Merrill-Sands, D., Gapasin, D. P., \& Mabesa, V. L. (1995). Women Scientists and Managers in Amicuhural Research in the Philinnines (ISNAR Research Report No. 7). The Hague: International Service for Agricultural Research.

[21] Fox, M. F. (1991). Gender, environmental milieu, and productivity in science. In Zuckerman, H. Cole, J. R. \&. Bruer J. T (Eds.). The Outer Circle: Women in the Scientific Community (Pg. 171- 204). New York: W. W. Norton and Company.

[22] Ferreira, V. (1997) Affirmative action and employment segregation in Portugal. Paper presented at the 3rd European Feminist Research Conference, Coimbra.

[23] Guy, M. E. (1995). Women, public administration, and the personnel function. In S. Hays \& R. C. Kearney (Eds.), Public personnel administration: Problems and prospects, 3rd ed. (pg. 232-246). Englewood Cliffs, NJ: Prentice Hall.

[24] Newman, M.A. (1993). Career advancement: Does gender make a difference? Federal civil service. Public Administration Review, 54(6), 507-514

[25] Primack, R. B., \& O’Leary, V. (1993). Cumulative disadvantages in the careers of women ecologists. Bioscience. 43(March 3), 158-1 65.

[26] Sonnert, G. (1995). What makes a good scientists? Determinants of peer evaluation among biologists.Social Studies of Science. 25, 35-55. 